\title{
Prediction of Major Adverse Cardiovascular Events (MACCE) Following Percutaneous Coronary Intervention Using ANFIS-PSO Model
}

\section{Sahar Dehdar Karsidani}

Hamadan University of Medical Sciences

Maryam Farhadian ( $\square$ maryam_farhadian80@yahoo.com )

Hamadan University of Medical Sciences

Hossein Mahjub

Hamadan University of Medical Sciences

Azadeh Mozayanimonfared

Hamadan University of Medical Sciences

\section{Research Article}

Keywords: Percutaneous Coronary Intervention, Major Adverse Cardiac Events, Adaptive Neuro fuzzy Inference systems, Particle Swarm Optimization

Posted Date: February 15th, 2022

DOI: https://doi.org/10.21203/rs.3.rs-1309684/v1

License: (9) This work is licensed under a Creative Commons Attribution 4.0 International License. Read Full License 


\section{Abstract}

Background: This study aimed to use the hybrid method based on an adaptive neuro-fuzzy inference system (ANFIS) and particle swarm optimization (PSO) to predict the occurrence of major adverse cardiac and cerebrovascular events (MACCE) of patients underwent angioplasty.

Method: This is a retrospective cohort study comprised a total of 220 patients (69 women and 151 men) who underwent coronary angioplasty in Ekbatan medical center in Hamadan city, Iran between March 2009 until March 2012. The occurrence and non-occurrence of MACCE, (including death, CABG, stroke, repeat revascularization) were considered as a binary outcome. The performance of ANFIS models for predicting MACCE was compared with ANFIS-PSO and logistic regression.

Results: Ninety-six patients (43.6\%) experienced the MACCE event after ten years of follow-up. In multivariate analysis based on logistic regression model, variables such as age $(\mathrm{OR}=1.05)$, smoking (OR = 3.53), diabetes $(O R=2.17)$ and stent length $(O R=3.12)$ had a significant effect on MACCE occurrence. Comparing the prediction performance of the models showed that the ANFIS-PSO model had higher accuracy $(89 \%)$ compared to the ANFIS (81\%) and logistic regression (72\%) in the prediction of MACCE.

Conclusion: The performance of ANFIS-PSO has a minimum error and maximum accuracy compared to other models in the prediction of MACCE. Application of this model is recommended for intelligent monitoring of these patients, the classification of high-risk patients and the allocation of necessary medical and health resources based on the needs of these patients.

\section{Introduction:}

The most common cardiovascular disease is coronary artery disease, which presents as ischemia and acute myocardial infarction. It is estimated that more than 23.6 million deaths in various communities will be due to cardiovascular disease [1]. Coronary artery disease is the first and most common cause of death in Iranians of all ages [2].

One of the major complications of the cardiovascular system is atherosclerosis or blockage of the arteries that supply blood to the heart. Bypass surgery, balloon angioplasty, and stent implantation are some of the most important therapeutic interventions used to treat clogged arteries [3]. A stent is a wired metal mesh tube that is used to keep the blood supply to the artery at the blocked point open. Angioplasty is a less invasive and cheaper procedure than coronary artery bypass graft surgery. In addition, it only requires 1 to 2 days of hospitalization, and the patient can return to work sooner and start his activity [4].

Non-fatal myocardial infarction events, cardiac death, and the need to restore blood flow are major adverse cardiovascular events that may occur to any patient after stent implantation. Due to the increasing demand for stent angioplasty, predicting the occurrence and identifying potential risk factors for subsequent major cardiovascular events can be effective in improving patients' survival and quality of life [5]. 
The development of an expert system, especially an adaptive neuro-fuzzy inference system (ANFIS) method, over the past few decades has made accurate predictions possible in many areas of medicine [6, 7]. The most important advantages of these systems are: expression of human knowledge using special linguistic concepts and fuzzy rules, nonlinearity and compatibility, and better accuracy of these methods in terms of data constraints compared to other methods $[8,9]$. Another new modeling method is artificial neural networks, the most important reason for the strength is their ability to be learned from input and output training patterns. The combination of fuzzy systems, which are based on logical rules, and artificial neural networks with the ability to knowledge acquisition from numerical information, enables us to use human knowledge in the construction of the prediction model [10]. Therefore, this study aimed to predict the occurrence of major adverse cardiac (MACCE) in patients undergoing stent angioplasty using the ANFIS model.

\section{Method:}

This retrospective cohort study comprised 220 patients underwent coronary angioplasty in Ekbatan Medical Center in Hamadan city, Iran from March 2009 to March 2012. From the beginning of September 2020 after at least 10 years of follow-up, the clinical condition of patients was followed up by telephone interview or in-person contact or by using the patients' medical records from the treating physician's office or hospital.

Patients' information including demographic characteristics, number of involved vessels, the number and type of stent (metal, drug), stent size, height and length, history of smoking, history of diabetes, hypertension, and hyperlipidemia extracted from patient records. The occurrence and non-occurrence of MACCE (including death, CABG, stroke, repeat revascularization) were considered as a binary outcome.

The Risk score variable is defined as the sum of risk factors including diabetes, smoking, hypertension, and hyperlipidemia. If the person has the desired symptom, the value is 1 , and if the symptom not exists, the value takes 0 , so when the value of the risk score is 2 for an individual, it means that the person has 2 risk factors.

Predictive models including ANFIS, PSO-ANFIS, and logistic regression were examined to predict the occurrence of MACCE. The odds ratio and $95 \%$ confidence interval were used to summarize and describe the data in the logistic regression model.

ANFIS as a fuzzy Takagi-Sugno system is based on if-then rules and benefits the learning skill of artificial neural networks together with decision-making capability of fuzzy-logic [11]. The ANFIS structure is formed of five layers. The first layer performs the fuzzification process where the number and type of membership function are specified by a training system based on training data. Then, the rules are defined in the rule layer and the effect of each rule is calculated, which can also be called the inference layer. In the third layer, the effect of each rule is normalized according to the effect of other rules. For the fourth layer, the output of each rule is obtained, which calculates the weighted output. Finally, in the fifth layer, the outputs are added together to form the output of the fuzzy system. To create this network, 
several parameters such as the type of membership function, the number of functions, the learning method, and the number of repetitions (Epoch) must be optimized [11, 12].

The Particle swarm optimization (PSO) is a stochastic optimization technique bio-inspired by the social behavior found in nature such as the motion of bird flocks and schooling fish. In this population-based algorithm, the members of the population interact straightly with each other and solve the problem by exchange of their best experience and recalling valuable experiences of the past. The beginning of the algorithm in optimizing the parameters of membership functions in the ANFIS model is that after designing the initial FIS, a group of particles or solutions are randomly generated and initialized by moving these particles during successive iterations and by updating the position of the particles, they try to find the optimal solution to the problem. For each answer, the fit value of each particle is evaluated, and if a better fit value is obtained, the position of the particle is updated. In the next step, the best new position of the whole group is found, and if the stop criterion is met, the algorithm also stops [13, 14].

The input variables used in predictive models including sex, age, stent length, stent diameter, number of vessels, type of stent and risk score. ANFIS architecture was shown in figure 1. For all models; the data were divided randomly into two groups of training $(70 \%)$ and test $(30 \%)$ sets. The same test, training sets and input variables were used to compare the performance of different models. Data analysis was performed using SPSS software version 21 and fuzzy logic toolbox of Matlab20 software. The stop criterion in the present study was a maximum of 1000 epochs or an error of less than 0.01 . The best FIS was selected based on the lowest error rate.

\section{Ethics approval, consent to participate}

This study was approved by the Ethics Committee of Hamadan University of Medical Sciences with IR.UMSHA.REC.1398.017. Due to the retrospective nature of the study, the patient consent form was not signed. All the participants were informed on the purpose of the study, in response to a follow-up phone call, patients or their relatives responded if they wished. All methods were performed in accordance with the relevant guidelines and regulations.

\section{Results:}

At the end of the follow-up time, out of 220 patients, 96 patients (43.6\%) had experienced MACCE events. From those, 48 patients passed away (21.8\%), 16 patients (7.3\%) developed CABG, 5 patients had a nonfatal myocardial infarction $(2.3 \%)$ and 27 patients $(12.3 \%)$ required repeat revascularization. The results related to the distribution of different variables in terms of occurrence and non-occurrence of MACCE events are presented in Table 1. 
Table 1

Frequency distribution of related variables in according to the occurrence of MACCE event

\begin{tabular}{|c|c|c|c|c|c|c|}
\hline & Occurrence & & non-occurrence & & Total & \\
\hline Variable & $\mathbf{N}$ & $\%$ & $\mathbf{N}$ & $\%$ & $\mathbf{N}$ & $\%$ \\
\hline All & 96 & 43.6 & 122 & 56.4 & 220 & 100 \\
\hline \multirow[t]{2}{*}{ Age (year) } & Mean \pm SD & & Mean \pm SD & & & P-value* \\
\hline & $63.47 \pm 1.05$ & & $57.31 \pm 0.98$ & & & $<0.001$ \\
\hline Sex & $\mathbf{N}$ & $\%$ & $\mathbf{N}$ & $\%$ & $\mathbf{N}$ & $\%$ \\
\hline Female & 30 & 43.5 & 39 & 56.5 & 69 & 0.975 \\
\hline Male & 66 & 43.7 & 85 & 56.3 & 151 & \\
\hline Smoking & & & & & & 0.001 \\
\hline Yes & 39 & 61.9 & 24 & 38.1 & 63 & \\
\hline No & 57 & 36.3 & 100 & 63.7 & 157 & \\
\hline Diabetes & & & & & & $<0.001$ \\
\hline Yes & 31 & 77.5 & 9 & 22.5 & 40 & \\
\hline No & 65 & 36.1 & 115 & 63.9 & 180 & \\
\hline Hypertension & & & & & & 0.008 \\
\hline Yes & 47 & 54.7 & 39 & 45.3 & 86 & \\
\hline No & 49 & 36.6 & 85 & 63.4 & 134 & \\
\hline Hyperlipidemia & & & & & & 0.041 \\
\hline Yes & 31 & 55.4 & 25 & 44.6 & 56 & \\
\hline No & 65 & 39.6 & 99 & 60.4 & 164 & \\
\hline Stent length & & & & & & 0.003 \\
\hline$<20 \mathrm{~mm}$ & 51 & 36.2 & 90 & 63.8 & 141 & \\
\hline$>20 \mathrm{~mm}$ & 45 & 57 & 34 & 43 & 79 & \\
\hline Stent Diameter & & & & & & 0.784 \\
\hline $3 \mathrm{~mm}$ & 51 & 45.9 & 60 & 54.1 & 111 & \\
\hline $3.5 \mathrm{~mm}$ & 36 & 41.4 & 51 & 58.6 & 87 & \\
\hline
\end{tabular}

* T-Test **Chi-square Test Risk Score: SUM (Smoking, Diabetes, Hypertension, and Hyperlipidemia) 


\begin{tabular}{|c|c|c|c|c|c|c|}
\hline & Occurrence & & non-occurrence & & Total & \\
\hline $4 \mathrm{~mm}$ & 9 & 40.9 & 13 & 59.1 & 22 & \\
\hline Number of vessels & & & & & & 0.252 \\
\hline 1 & 48 & 40 & 72 & 60 & 120 & \\
\hline 2 & 31 & 44.9 & 38 & 55.1 & 69 & \\
\hline 3 & 17 & 56.7 & 13 & 43.3 & 30 & \\
\hline Type of stent & & & & & & 0.577 \\
\hline BMS & 60 & 42.3 & 82 & 57.7 & 142 & \\
\hline DES & 36 & 46.2 & 42 & 53.8 & 78 & \\
\hline Number of stents & & & & & & 0.078 \\
\hline 1 & 64 & 42.1 & 88 & 57.9 & 152 & \\
\hline 2 & 23 & 41.1 & 33 & 58.9 & 56 & \\
\hline 3 & 9 & 75 & 3 & 25 & 25 & \\
\hline Risk Score & & & & & & $<0.001$ \\
\hline 0 & 18 & 24 & 57 & 76 & 75 & \\
\hline 1 & 29 & 40.8 & 42 & 59.2 & 71 & \\
\hline 2 & 33 & 62.3 & 20 & 37.7 & 53 & \\
\hline 3 & 16 & 76.2 & 5 & 23.8 & 21 & \\
\hline
\end{tabular}


Table 2

Logistic regression analyses of factors associated with MACCE event

\begin{tabular}{|c|c|c|c|c|c|c|}
\hline Variable & $\begin{array}{l}\text { Unadjusted Odds } \\
\text { Ratio }\end{array}$ & $95 \% \mathrm{Cl}$ & $\begin{array}{l}\mathrm{P} \text { - } \\
\text { value }\end{array}$ & $\begin{array}{l}\text { Adjusted Odds } \\
\text { Ratio }\end{array}$ & $95 \% \mathrm{Cl}$ & $\begin{array}{l}\mathrm{P}- \\
\text { value }\end{array}$ \\
\hline Age (year) & 1.05 & $\begin{array}{l}1.02- \\
1.08\end{array}$ & $<0.001$ & 1.05 & $1.02-1.09$ & 0.001 \\
\hline Sex & & & & & & 0.997 \\
\hline Female & Reference & & & Reference & & \\
\hline Male & 1.009 & $\begin{array}{l}0.56- \\
1.79\end{array}$ & & 0.99 & $0.44-2.22$ & \\
\hline Smoking & & & 0.001 & & & 0.002 \\
\hline No & Reference & & & Reference & & \\
\hline Yes & 2.85 & $\begin{array}{l}1.55- \\
5.21\end{array}$ & & 3.53 & $1.61-7.75$ & \\
\hline Diabetes & & & $<0.001$ & & & 0.001 \\
\hline No & Reference & & & Reference & & \\
\hline Yes & 6.09 & $\begin{array}{l}2.73- \\
13.59\end{array}$ & & 5.77 & $\begin{array}{l}2.05- \\
16.202\end{array}$ & \\
\hline Hypertension & & & 0.009 & & & 0.25 \\
\hline No & Reference & & & Reference & & \\
\hline Yes & 2.09 & $\begin{array}{l}1.205- \\
3.62\end{array}$ & & 1.57 & $0.72-3.39$ & \\
\hline Hyperlipidemia & & & 0.042 & & & 0.238 \\
\hline No & Reference & & & Reference & & \\
\hline Yes & 1.88 & $\begin{array}{l}1.02- \\
3.48\end{array}$ & & 1.62 & $0.72-3.63$ & \\
\hline Stent length & & & 0.003 & & & 0.003 \\
\hline$<20 \mathrm{~mm}$ & Reference & & & Reference & & \\
\hline$>20 \mathrm{~mm}$ & 2.33 & $\begin{array}{l}1.33- \\
4.09\end{array}$ & & 3.12 & $1.48-6.57$ & \\
\hline Stent Diameter & & & 0.784 & & & 0.316 \\
\hline $3 \mathrm{~mm}$ & Reference & & & Reference & & \\
\hline $3.5 \mathrm{~mm}$ & 0.83 & $\begin{array}{l}0.47- \\
1.46\end{array}$ & & 0.57 & $0.27-1.18$ & \\
\hline
\end{tabular}




\begin{tabular}{|c|c|c|c|c|c|c|}
\hline Variable & $\begin{array}{l}\text { Unadjusted Odds } \\
\text { Ratio }\end{array}$ & $95 \% \mathrm{Cl}$ & $\begin{array}{l}\mathrm{P} \text { - } \\
\text { value }\end{array}$ & $\begin{array}{l}\text { Adjusted Odds } \\
\text { Ratio }\end{array}$ & $95 \% \mathrm{Cl}$ & $\begin{array}{l}P- \\
\text { value }\end{array}$ \\
\hline $4 \mathrm{~mm}$ & 0.81 & $\begin{array}{l}0.32- \\
2.06\end{array}$ & & 0.73 & $0.24-2.23$ & \\
\hline $\begin{array}{l}\text { Number of } \\
\text { vessels }\end{array}$ & & & 0.258 & & & 0.67 \\
\hline 1 & Reference & & & Reference & & \\
\hline 2 & 1.22 & $\begin{array}{l}0.67- \\
2.22\end{array}$ & & 1.02 & $0.37-2.74$ & \\
\hline 3 & 1.96 & $\begin{array}{l}0.87- \\
4.406\end{array}$ & & 1.73 & $0.41-7.31$ & \\
\hline Type of stent & & & 0.570 & & & 0.99 \\
\hline BMS & Reference & & & Reference & & \\
\hline DES & 0.85 & $\begin{array}{l}0.49- \\
1.48\end{array}$ & & 1.002 & $0.47-2.13$ & \\
\hline $\begin{array}{l}\text { Number of } \\
\text { stents }\end{array}$ & & & 0.110 & & & 0.242 \\
\hline 1 & Reference & & & Reference & & \\
\hline 2 & 0.96 & $\begin{array}{l}0.51- \\
1.79\end{array}$ & & 0.84 & $0.38-1.85$ & \\
\hline 3 & 4.12 & $\begin{array}{l}1.07- \\
15.84\end{array}$ & & 3.49 & $\begin{array}{l}0.69- \\
17.49\end{array}$ & \\
\hline
\end{tabular}

Table 3

ANFIS system and ANFIS-PSO architecture and training parameter

\begin{tabular}{|ll|}
\hline Fuzzy System & Sugeno \\
\hline Membership Function & $\begin{array}{l}\text { Input: Gaussian } \\
\text { Output: Linear }\end{array}$ \\
\hline Training Algorithm & back propagation \\
\hline Max epoch & 1000 \\
\hline Initial Step Size & 0.01 \\
\hline Step Size Decrease Rate & 0.9 \\
\hline Step Size Increase Rate & 1.1 \\
\hline Error Goal & 0 \\
\hline
\end{tabular}


The mean age of people with MACCE $(63.47 \pm 1.05)$ was significantly higher than people without the experience of MACCE $(57.31 \pm 0.98)(p<0.001)$. No statistically significant difference was found in the distribution of MACCE events between the two sexes $(p=0.975)$. Approximately $43 \%$ of patients of both sexes had MACCE events. Smoking had a significant effect on the incidence of MACCE $(p<0.001)$, so that out of 63 smokers, 39 (63.9\%) had MACCE, while out of 157 non-smokers, only 57 patients (36.3\%) had experienced MACCE. Diabetes also had a significant effect on the MACCE $(p=0.001)$, from 40 diabetic patients, 31 (77.5\%) had MACCE, while out of 180 non-diabetic patients, 65 (36.1\%) had MACCE. Blood pressure and MACCE occurrence were also significantly associated $(p=0.008)$. Among 134 people who did not have high blood pressure, $49(36.6 \%)$ had MACCE, while from 86 high blood pressure patients, 47 (54.7\%) had MACE. The relationship between hyperlipidemia and the length of the embedded stent with MACCE occurrence was also statistically significant $(p<0.05)$. Variable such as stent number, stent type, stent diameter and the number of involved vessel had no significant effect on the MACE event.

In the multivariate analysis based on the logistic regression model, the effect of age, smoking, diabetes, and stent length on the MACCE event was significant. In this regard, the results showed that a one-year increase at the age will increase the $5 \%$ chance of MACCE occurrence ( $95 \% \mathrm{Cl}$ : 1.02-1.09). Diabetes also increases the chance of developing MACCE by 5.77 times (95\% Cl: 2.05-16.202). The chance of developing MACCE in smokers is 3.5 times non-smokers (95\% Cl: 1.61-7.75). Also, the chance of MACCE occurrence in people who have a stent length greater than $20 \mathrm{~mm}$ is 3.12 times those in whom the stent length is less than $20 \mathrm{~mm}$ (95\% Cl: 1.48-6.57).

The performance of the different predictive models in the training and test phase is presented in a table. The process of error changes during the training process for the ANFIS and ANFIS-PSO models is presented in Figure 2. Finally, a comparison of the prediction performance of three models in the form of sensitivity, specificity, and accuracy indices is presented in Table 4.

Table 4

Predictive performance of ANFIS, ANFIS-PSO and Logistic Regression on the test and train sets

\begin{tabular}{|lllllll|}
\hline $\begin{array}{l}\text { Classification } \\
\text { method }\end{array}$ & Train & \multicolumn{5}{c|}{ Test } \\
\cline { 2 - 7 } & Accuracy & Specificity & Sensitivity & Accuracy & Specificity & Sensitivity \\
\hline ANFIS & 0.81 & 0.92 & 0.69 & 0.84 & 0.91 & 0.78 \\
\hline ANFIS-PSO & 0.89 & 0.89 & 0.88 & 0.90 & 0.99 & 0.82 \\
\hline Logistic Regression & 0.72 & 0.85 & 0.53 & 0.71 & 0.79 & 0.62 \\
\hline
\end{tabular}

\section{Discussion:}

In this study, the long-term (10-year) survival status of cardiovascular patients undergoing angioplasty was evaluated. Also, to predict the occurrence of MACCE, the performance of logistic regression model as the most common classical model, ANFIS and ANFIS-PSO as a data mining model were compared. 
One of the features of the present study is that it evaluates the long-term survival of patients, while other studies mainly consider short intervals (6 months). Also, in these studies, the main focus has been on comparing the survival of patients in two types of metal and drug stents. The present study was a cohort study in which no randomization was performed, so it was not possible to directly compare patient survival in two types of drug and metal stents. However, to modify its effect, this variable is added to the model.

The results show that $43.7 \%$ of patients experienced MACCE at the end of the follow-up period. While in the study conducted by Aghajani et al., the incidence of MACCE for 10-year follow-up was $14.4 \%$ [15]. In the study conducted by Spinola et al., based on the 313 patients over a ten-year period, $28 \%$ of these patients had experienced MACCE [16]. In the Meliga et al., study, which was conducted in seven American and European centers over 3-year follow-up period, MACCE events occurred in $26.5 \%$ of patients [17].

In multivariate analysis based on logistic regression model, the effect of variables such as age, smoking, diabetes and stent length was significant. The results indicate that the risk of MACCE in diabetic patients is significantly higher than non-diabetic patients $(O R=2.17)$. Similar results were observed by Aghajani et al., (OR = 1.33) [14], Meliga et al., (OR = 2.85) [17] and Cai et al., (OR 2.91) [18], Tsai et al., [19] and Farshidi et al., [20].

As expected, risk factors such as older age and smoking increase the risk of MACCE occurrence and are in accordance with the findings of Farshidi et al., and Tsai et al., [19, 20].

Also, patients with 3 stents implanted were 1.8 times more likely to have MACCE events than patients with 1 stent. This result was also confirmed in the Tsai et al., [19].

The ANFIS-PSO had a high accuracy in predicting the MACCE event compared to the ANFIS and the logistic regression models. Various studies have used classical and machine learning approaches to predict cardiovascular disease, for example: Taghizadeh et al., compared ANFIS and logistic regression in predicting death after coronary artery bypass graft surgery. Their study evaluated the data of 824 patients including age, sex, BMI, hypertension, diabetes (mellitus), blood cholesterol, peripheral vascular disease, addiction, smoking, history of chronic heart failure, etc as input variables. The FCM method was used to create FIS model, Gaussian and linear membership functions were used for inputs and output. Sensitivity, specificity, accuracy were reported ANFIS $67 \%, 97 \%$ and $96 \%$ and in logistic regression $48 \%, 89 \%$ and $89 \%$, respectively [10].

In recent years, due to the emergence of hybrid prediction methods that help in screening and predicting the consequences of the disease, diagnosis and prediction in the field of medicine has made significant progress. According to the performance of ANFIS-PSO more considerable than traditional ANFIS and logistic regression in the prediction of MACCE. Application of this model is recommended for intelligent monitoring of these patients, the classification of high-risk patients and the allocation of necessary medical and health resources based on the needs of these patients. 


\section{Declarations:}

Conflict Of Interest

There are no conflicts of interest.

\section{Funding}

This study was supported by Vice-Chancellor of Research and Technology of Hamadan University of Medical Sciences, Contractor No. 980210772.

\section{Acknowledgment}

This research was founded and supported by a grant (no. 980210772) from Hamadan University of Medical Sciences.

\section{Availability of data and materials}

The datasets during and/or analyzed during the current study available from the corresponding author on reasonable request.

\section{Authors' Contributions}

SD contributed to preparation of the proposal, collected the data, prepare results, and revising the article

MF prepare proposals, set and analysis the results and their interpretation, prepare and interpret data, writing the article

HM prepare proposals, supervised the design and execution of the study and revising the article.

AM contributed to preparation of the proposal, collected the data and revising the article

All authors reviewed the manuscript

\section{References:}

1. Fischman DL, Leon MB, Baim DS, Schatz RA, Savage MP, Penn I, et al. A randomized comparison of coronary-stent placement and balloon angioplasty in the treatment of coronary artery disease. New England Journal of Medicine. 1994;331(8):496-501.

2. Adeli A, Neshat M, editors. A fuzzy expert system for heart disease diagnosis. Proceedings of International Multi Conference of Engineers and Computer Scientists, Hong Kong; 2010.

3. Gaziano TA. Cardiovascular disease in the developing world and its cost-effective management. Circulation. 2005;112(23):3547-53. 
4. Mahmoodi A, Asgarimoghadam R, Moazam M, Sadeghian S. Identify models predict coronary artery disease using Neural networks and variable selection based on classification and regression tree. $J$ Shahrekord Med Sci Uni. 2014;15:22-7.(in Persian).

5. Euroaspire I. Lifestyle and risk-factor management and use of drug therapies in coronary patients from 15 countries. European heart journal. 2001;22(7):554-72.

6. Asaad Sajadi N, Borzouei Sh, Mahjub H, Farhadian M. Diagnosis of hypothyroidism using a fuzzy rule-based expert system. Clinical Epidemiology and Global Health. 2019; 7: 519-524. DOl:https://doi.org/10.1016/j.cegh.2018.11.007

7. Sultana M, Haider A, Uddin MS, editors. Analysis of data mining techniques for heart disease prediction. 2016 3rd international conference on electrical engineering and information communication technology (ICEEICT); 2016: IEEE.

8. Shafiee $\mathrm{H}$, Ebrahimi M. Accurate prediction of coronary artery disease using bioinformatics algorithms. Qom University of Medical Sciences Journal. 2016;10(4):22-35.

9. Asaad Sajadi N, Borzouei S, Mahjub H, Farhadian M. Diagnosis of hypothyroidism using a fuzzy rulebased expert system. Clinical Epidemiology and Global Health. 2019; 7 (4): 519-524

10. Taghizadeh Nouei M, Vahidian Kamyad A, Sarzaeem M, Ghazalbash S. Fuzzy risk assessment of mortality after coronary surgery using combination of adaptive neuro-fuzzy inference system and Kmeans clustering. Expert Systems. 2016;33(3):230-8.

11. Karaboga, D., Kaya, E. Adaptive network based fuzzy inference system (ANFIS) training approaches: a comprehensive survey. Artif Intell Rev. 2019; 52: 2263-2293.

12. Yadollahpour A, Nourozi J, Mirbagheri SA, Simancas-Acevedo E, Trejo-Macotela FR. Designing and implementing an ANFIS based medical decision support system to predict chronic kidney disease progression. Frontiers in physiology. 2018;9:1753.

13. Zhi-Hui Zhan, Jun Zhang, Yun Li, and Henry Shu-Hung Chung. Adaptive particle swarm optimization. IEEE Transactions on Systems, Man, and Cybernetics, Part B (Cybernetics). 2009; 39(6):1362-1381.

14. Neshat M, Rezaei M. Aipso: adaptive informed particle swarm optimization. In 2010 5th IEEE International Conference Intelligent Systems, pages 438-443. IEEE, 2010.

15. Aghajani H, Nezami P, Shafiee A, Jalali A, Nezami A, Nozari Y, et al. Predictors of Long-term Major Adverse Cardiac Events Following Percutaneous Coronary Intervention in the Elderly. Archives of Iranian medicine. 2018;21(8):344-8.

16. Espinola-Klein C, Rupprecht H-J, Erbel R, Nafe B, Brennecke R, Meyer J. Impact of restenosis 10 years after coronary angioplasty. European heart journal. 1998;19(7):1047-53.

17. Meliga E, Garcia-Garcia HM, Valgimigli M, Chieffo A, Biondi-Zoccai G, Maree AO, et al. Longest available clinical outcomes after drug-eluting stent implantation for unprotected left main coronary artery disease: the DELFT (Drug Eluting stent for LeFT main) Registry. Journal of the American College of Cardiology. 2008;51(23):2212-9.

18. Cai A, Dillon C, Hillegass WB, Beasley M, Brott BC, Bittner VA, et al. Risk of major adverse cardiovascular events and major hemorrhage among White and Black patients undergoing 
percutaneous coronary intervention. Journal of the American Heart Association. 2019;8(22):e012874.

19. Farshidi H, Abdi A, Madani A, Moshiri S, Ghasemi A, Hakimian R. Major adverse cardiovascular event (MACE) after percutaneous coronary intervention in one-year follow-up study. Electronic physician. 2018;10(2):6383.

20. Tsai IT, Wang CP, Lu YC, Hung WC, Wu CC, Lu LF, et al. The burden of major adverse cardiac events in patients with coronary artery disease. BMC cardiovascular disorders. 2017;17(1):1-13.

\section{Figures}

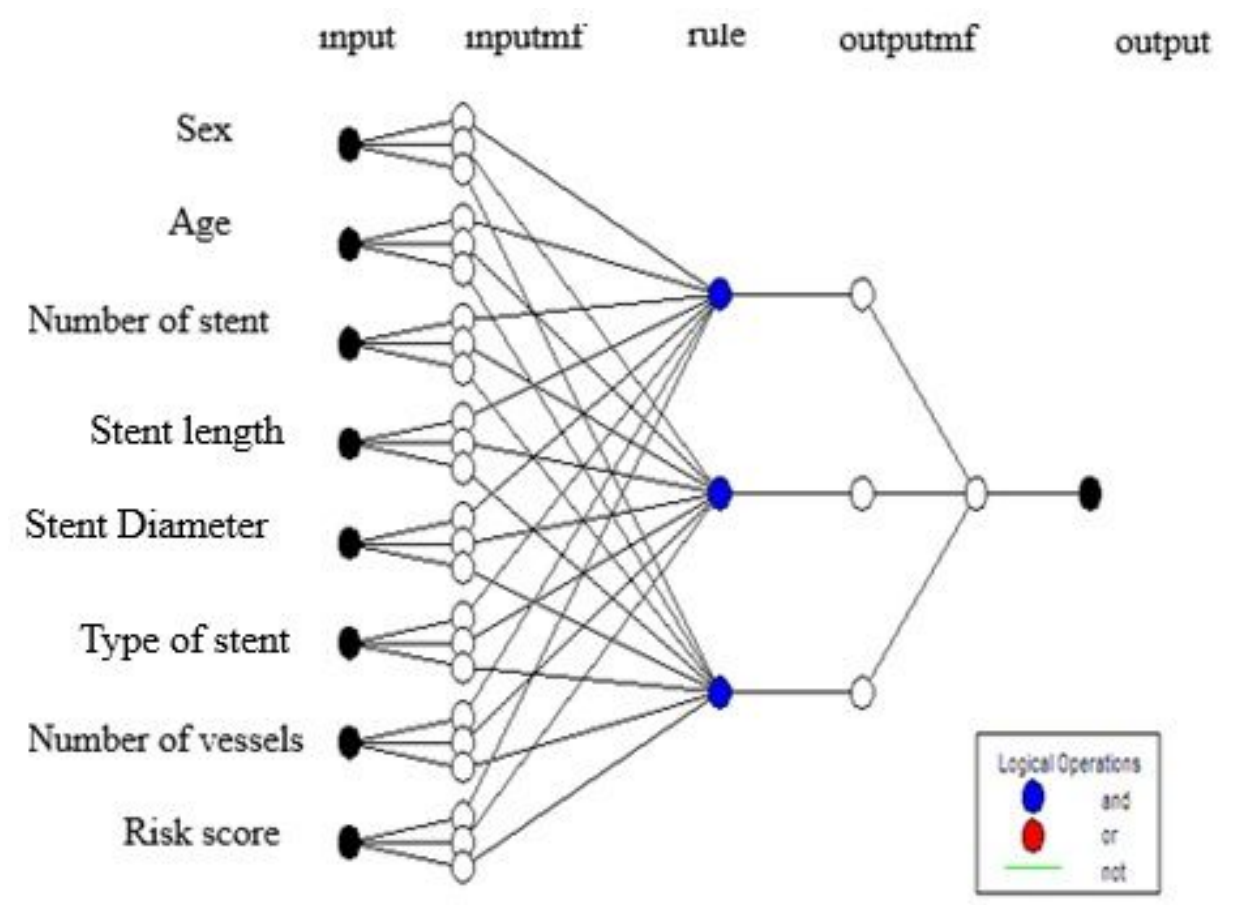

\section{Figure 1}

Legend not included with this version. 


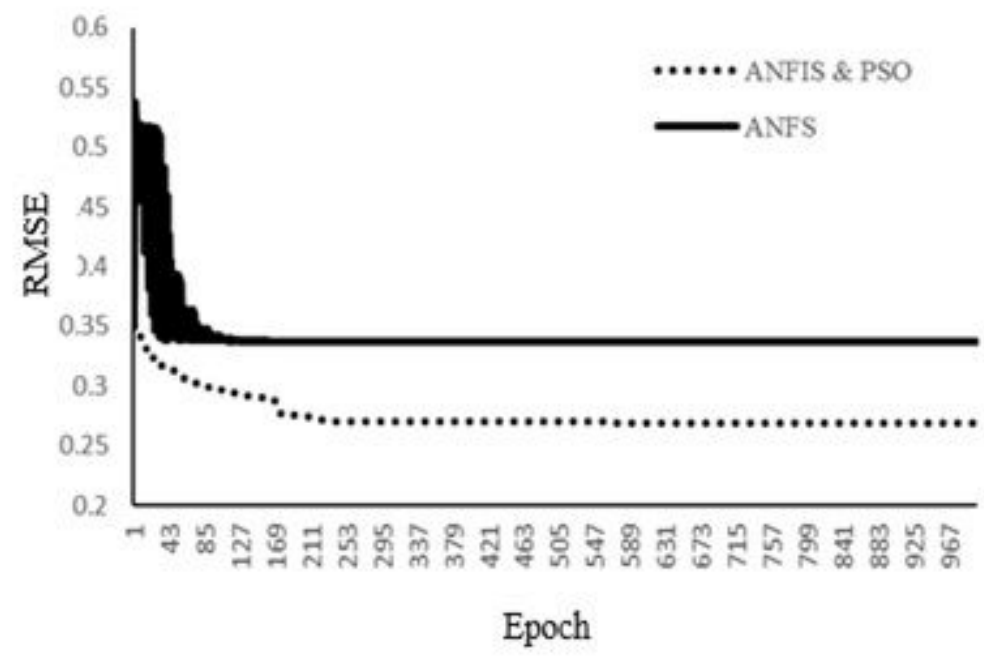

Figure 2

Legend not included with this version. 